\title{
Article
}

\section{Design and Experimental Evaluation of a Form Trimming Machine for Horticultural Plants}

\author{
Mao Li ${ }^{1,2}$, Lina Ma ${ }^{1,2}$, Wangyuan Zong ${ }^{1,2}$, Chengming Luo ${ }^{1,2, * \mathbb{C}}$, Muchang Huang ${ }^{1}$ and Yang Song ${ }^{1}$ \\ 1 College of Engineering, Huazhong Agricultural University, Wuhan 430070, China; \\ leemone@webmail.hzau.edu.cn (M.L.); sunnylina@mail.hzau.edu.cn (L.M.); zwy@mail.hzau.edu.cn (W.Z.); \\ muchanghuang@webmail.hzau.edu.cn (M.H.); yangsong@webmail.hzau.edu.cn (Y.S.) \\ 2 Key Laboratory of Agricultural Equipment in Mid-Lower Yangtze River, Ministry of Agriculture and \\ Rural Affairs, Wuhan 430070, China \\ * Correspondence: chmluo@mail.hzau.edu.cn; Tel.: +86-27-8728-2120
}

Citation: Li, M.; Ma, L.; Zong, W.; Luo, C.; Huang, M.; Song, Y. Design and Experimental Evaluation of a Form Trimming Machine for Horticultural Plants. Appl. Sci. 2021, 11, 2230. https://doi.org/10.3390/ app11052230

Academic Editor: Dimitrios Kateris

Received: 11 February 2021

Accepted: 28 February 2021

Published: 3 March 2021

Publisher's Note: MDPI stays neutral with regard to jurisdictional claims in published maps and institutional affiliations.

Copyright: (c) 2021 by the authors. Licensee MDPI, Basel, Switzerland. This article is an open access article distributed under the terms and conditions of the Creative Commons Attribution (CC BY) license (https:// creativecommons.org/licenses/by/ $4.0 /)$.

\begin{abstract}
Form trimming is an important practice in horticulture. Currently, handheld trimming tools are the most commonly used in China, which presents certain disadvantages including high human labor input, low productivity and inconsistent performance. In this work, a wheeled form trimming machine was designed for shrub plants with the aim of reducing labor input, increasing efficiency and improving trimming performance. The machine was mainly composed of three parts: a supporting frame, a rotary base and a knife system. The design and construction of the key components of the machine were introduced. The knife system was a combination of multiple cutter units with reciprocating motions. The number of units and their connecting angles could be adjusted to realize different trimming shapes. The knife system was carried by the rotary base and could realize $360^{\circ}$ rotations to cut the plants into a desired form. Experiments were performed to determine the optimal working parameters (cutting frequency of the cutter unit and rotating speed of the rotary base). The similarity between the plant profile after trimming and the profile of the knife system and the consumed time in each operation were chosen as two evaluation indexes. Results showed that when the cutting frequency was $16.7 \mathrm{~Hz}$ and the rotating speed of the rotary base was $13.5 \mathrm{r} / \mathrm{min}$, the trimming operation could be completed by two circles, and the time consumption was $8.89 \mathrm{~s}$. Furthermore, to test the adaptability of the machine, five different shrub plants were chosen and trimmed by the machine, and results showed that the overall similarity was above $93 \%$. Therefore, the form trimming machine developed could meet the requirements of shrub trimming in horticulture with desirable precision and adaptability.
\end{abstract}

Keywords: form trimming machine; rotational cutting; horticulture

\section{Introduction}

The green area per capita is an important index of the living environment and quality of life in a city. From 2000 to 2017, the area of vegetation coverage increased by 5\% in the world and one quarter of that amount was contributed by China [1]. According to the report "Global Urban Land Composite and Expansion" from the National Remote Sensing Center of China, the green area per capita in cities increased from $23.14 \mathrm{~m}^{2}$ in 2000 to $40.47 \mathrm{~m}^{2}$ in 2020 on a global scale [2]. A rapid increase in green spaces (parks, gardens) in the cities means a booming horticulture industry and an increasing demand for supporting technologies and facilities. Pruning and trimming are common practices in horticulture. The superfluous or dead/diseased branches, twigs, leaves, and buds of horticultural plants need to be cut off on a regular basis. This practice is important for keeping the beauty of the landscape, promoting a healthy growth and adjusting the blossoms of plants [3-5].

Shrubs are a common type of horticultural plants used for landscape. They require regular trimming to keep desired forms and sizes. Although the horticulture industry is developing rapidly, the mechanization and automation level of some common practices 
is relatively low, especially in China [6]. Currently, form trimming of shrubs is mainly performed by human operators using handheld shears and trimmers. Obvious disadvantages include high human labor input, low productivity and inconsistent performance. Therefore, to provide a time-and-energy efficient solution for shrub trimming is of great value in promoting horticultural mechanization.

Through a comprehensive literature survey, there exists a significant body of work on trimming machines for various plants, such as grass [7,8], coconut [9], spinach [10,11], and hedge [12]. However, there are very few studies on form trimming of shrubs or bushes. Since each plant has its particular physical and mechanical properties, and the trimming requirements for different plants vary, the structural designs of those trimming machines cannot be directly applied in form trimming for shrubs. The most recent work on shrub trimming is reported in [13], in which a robotic arm with a vision system and a motion planning algorithm was developed. A circular double-blade cutter was mounted onto the robotic arm as the end-effector and was guided by the motion planning algorithm to cut a shrub plant into a designed shape. The accuracy of the system was tested to be lower than required, and further improvement on the vision system was suggested. Some machinery companies in Europe, such as Orlandi Group of Italy and Lanz Technik of Germany, have produced ground support trimming machines for form trimming of plants to reduce human labor demand. However, the design principles of those machines were not clear and no performance evaluation were performed.

Cutters and blades are important working parts in trimming machines for agriculture and horticulture. A series of work were conducted on designing suitable cutting elements and determining their optimal working parameters for trimming crops [14-16], fruit trees [17-19] and landscaping plants [20] etc. Such as in [21], the optimal combination of cutting speed, cutting gap and blade bevel angle were experimentally determined for the moving blade of a trimming tool for longan branches, and in [22], the optimal fruit feeding rate, rotating speed of the trimmed fruit and the knife height were experimentally determined for an automatic trimming machine for young coconut fruit. Overall, there are two main types of cutters used for plant cutting and trimming: disc type and blade type. Disc cutters are commonly used in cutting crops, vegetables, grasses and tree twigs through continuous rotations. The blade type can have various mechanical configurations, such as single moving blade, double moving blades, double blades with one blade moving and one fixed, multiple blades, and various motion types: circular, angular, and linear. Currently, the blade type cutters with linear reciprocating motion are mainly used in agricultural harvesters for grain crops. Double blade cutters, with one set of linearly moving blades or two sets of oppositely moving blades, are commonly seen on trimmers of tree branches and hedges. These machines are usually handheld, and form trimming cannot be realized without human operators' maneuvers.

Overall, with the rapid development of horticulture industry, the demand for more advanced horticultural machinery is increasing. The aim of this work is to design and test a form trimming machine for shrubs so that this labor-intensive operation can be completed by a more efficient and automatic solution. The design method and experimental evaluation process reported herein can be applied in developing form trimming machines for horticultural plants to promote the mechanization and automation level of trimming operation.

The remainder of the paper is organized as follows. The design of the form trimming machine and its key components are introduced in Section 2. Then, experiments for determining the optimal parameters and capacities of the machine and for testing the adaptability of the machine are detailed in Section 3. Results and discussions are presented in Section 4. The conclusions are drawn in Section 5. 


\section{Design of the Form Trimming Machine}

\subsection{Oveall Structure and Working Principle}

The two main forms of shrub plants are spherical and conical, i.e., balls and cones, both of which can be shaped by revolving motions of the cutter. The general working principle of the designed form trimming machine was to rotate a flexible cutter by $360^{\circ}$ to complete trimming of the plant. The contour of the cutter could be adjusted to form different shapes.

Figure 1 shows the overall structure and a prototype of the form trimming machine, which consisted of three main parts: a supporting frame with wheels, a rotary base and a knife system. The form trimming operation was completed with a combination of two motions: rotation of the rotary base and reciprocating motion of the cutter units of the knife system. The supporting frame was made of hollow square steel tubes to make the structure sturdy and light weight. The machine used two groups of wheels for supporting and transporting, two standard wheels and two caster wheels with locks, so that the machine can be easily moved and fixed. For easy maintenance and control, the machine used lithium batteries as the power source and electric motors for driving the working components. The rotary base was mounted on the frame through a pair of steel bars. The height of the rotary base could be adjusted to fit different heights of the plants. The knife system was carried by the rotary based and could perform $360^{\circ}$ rotations under its driving. The details of the parameters of the machine are shown in Table 1.

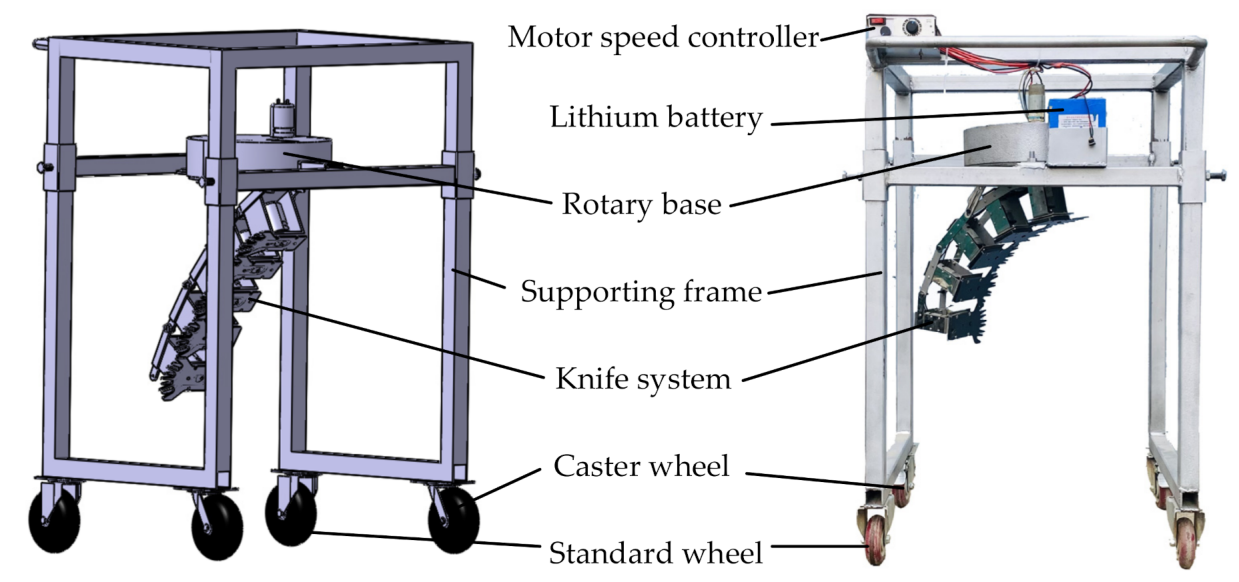

Figure 1. Overall structure and prototype of the designed form trimming machine.

Table 1. Parameters of the designed form trimming machine.

\begin{tabular}{cc}
\hline Parameter & Value (Unit) \\
\hline Overall dimensions (length $\times$ width $\times$ height) & $680 \times 725 \times 1075 \mathrm{~mm}$ \\
Total weight & $53.5 \mathrm{~kg}$ \\
Knife system weight & $4.9 \mathrm{~kg}$ \\
Adjustable height range & $0 \sim 925 \mathrm{~mm}$ \\
Maximum plant size & $700 \mathrm{~mm}$ \\
Power requirement & $24 \mathrm{VDC}$ \\
\hline
\end{tabular}

The rotary base and the knife system were the two key working components of the machine. Their design and construction details are given as follows. 


\subsection{Rotary Base}

The rotary base provides the rotation motion required for the trimming operation. As shown in Figure 2, its main components included an upper cover, a driving motor, a slip ring, a motor coupling, a small driving gear, an internal driven gear, a slewing bearing and a lower cover.

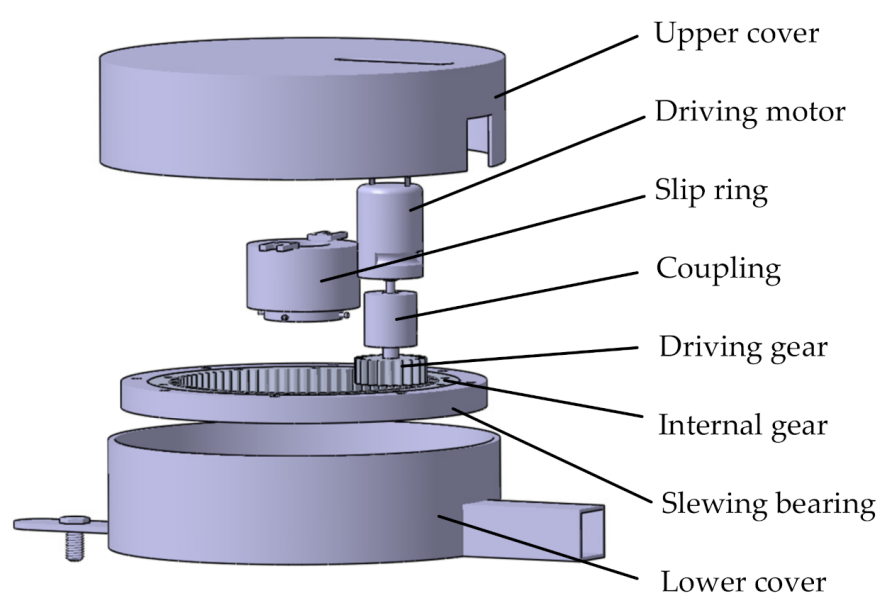

Figure 2. Structure of the rotary base.

A key working parameter of the trimming machine is the rotating speed of the rotary base. A value too large will result in misses of plant branches and poor trimming performance, while a value too small means low working efficiency. Since the rotation motion of the knife system is analogous to the forward motion of the cutter bar on combine harvesters of corn, rapeseed etc. in the field, we referred to the working speed of combine harvesters and determined an initial speed range for the rotary base. The following equation was used for calculation:

$$
n=\frac{60 \times v}{2 \pi r} \times 1000
$$

where $n$ is the rotating speed of the rotary base $(\mathrm{r} / \mathrm{min}), v$ is the maximum linear speed along the contour of the knife system $(\mathrm{m} / \mathrm{s}), r$ is the maximum rotating radius of the knife system $(\mathrm{mm})$. Generally, the field speeds of combine harvesters for crops are between $0.5 \mathrm{~m} / \mathrm{s}$ and $1.0 \mathrm{~m} / \mathrm{s}$ [23-25], i.e., $v$ in Equation (1) was $0.5 \sim 1.0 \mathrm{~m} / \mathrm{s}$. The maximum rotating radius of the knife system was about $0.5 \mathrm{~m}$, i.e., $r=500$. Then, $n$ was calculated to be $9.5 \sim 19 \mathrm{r} / \mathrm{min}$. This range was set as an initial guideline for choosing the rotating speed for the rotary base. The optimal speed was determined through experiments after the cutter blades were chosen and the knife system was installed. The motor chosen for the rotary base was a 24V DC motor (model XD-37GB555, weight $310 \mathrm{~g}$ ) with a rated speed of $93 \mathrm{r} / \mathrm{min}$ and rated torque of $8 \mathrm{~kg} \cdot \mathrm{cm}$. Through the internal gear mesh, which had a reduction of $4: 1$, the torque transferred to the knife system was about $32 \mathrm{~kg} \cdot \mathrm{cm}$, and the maximum rotating speed available for the rotary base was about $23.3 \mathrm{r} / \mathrm{min}$.

\subsection{Knife System}

\subsubsection{Structure}

In order to fit different forms and sizes of shrub plants, the knife system needs to be flexible and can adjust shapes. In the designed machine, the knife system was a combination of multiple cutter units. As shown in Figure 3, the cutter units were connected in a sequence. Each unit was composed of a cutter holder, a driving motor, a driving gear, an internal gear with an eccentric wheel, a moving blade, and a fixed blade. The blades were made of $65 \mathrm{Mn}$ steel with $0.62 \sim 0.7 \%$ carbon and $0.9 \sim 1.2 \%$ manganese. The hardness of the blades was 
62HRC after a quenching heat treatment. The surface of the blades was coated with a layer of rust-resistant material so that the blades can have a long operating lifetime. To keep the whole knife system lightweight while ensuring enough cutting power, each cutter unit was driven by a small DC motor. The continuous rotations of the motor were converted into reciprocating swings of the moving blades through the eccentric gear mesh.

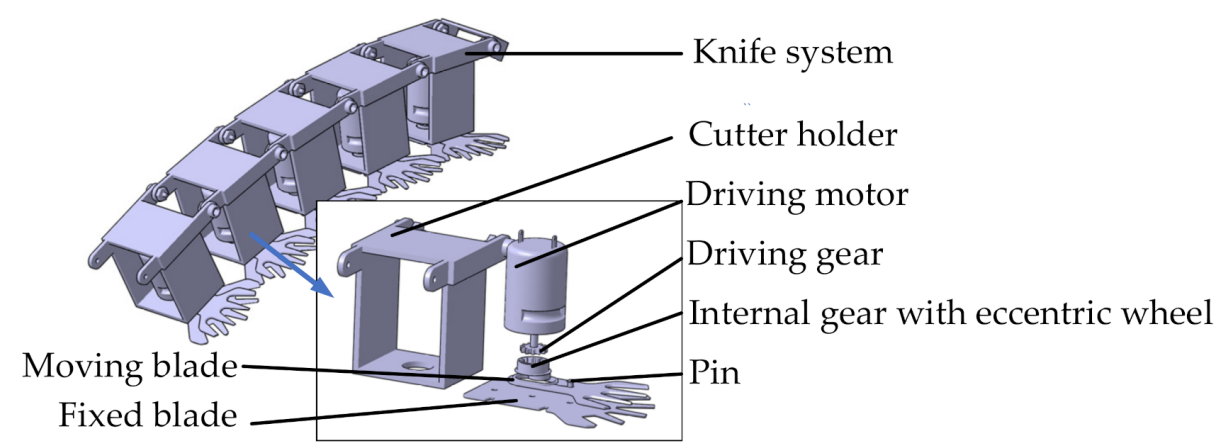

Figure 3. The knife system and the cutter unit.

The connecting angles of the cutter units could be adjusted to form different shapes for the knife system. The two commonly used shapes were a straight-line shape and an arc shape, respectively for cone form trimming and ball form trimming, as shown in Figure 4.

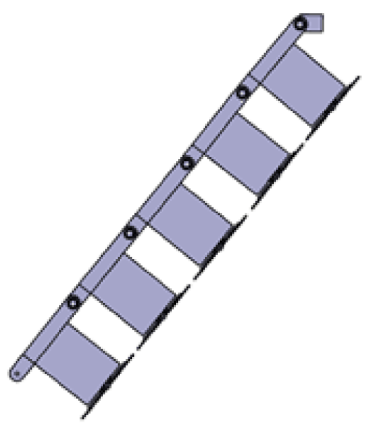

(a)

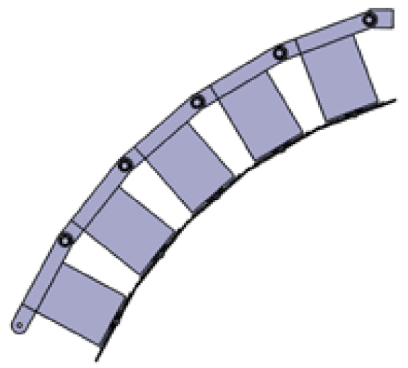

(b)

Figure 4. The knife system in different shapes: (a) Straight-line shape for trimming cones; (b) Arc shape for trimming balls.

\subsubsection{Principle of the Cutting Motion of Blades}

Each cutter unit contains one fixed blade and one moving blade. The moving blade swings back and forth to make a cutting function. Figure 5 shows the principle of the generation of reciprocating motion of the moving blade. The driving motor drives the inner gear with the eccentric wheel to rotate around the center $\left(O_{1}\right)$ of the inner gear, and then, drives the moving blade to rotate around the pin $(O)$. When the eccentric wheel rotates for one circle, the moving blade swings back and forth once. 

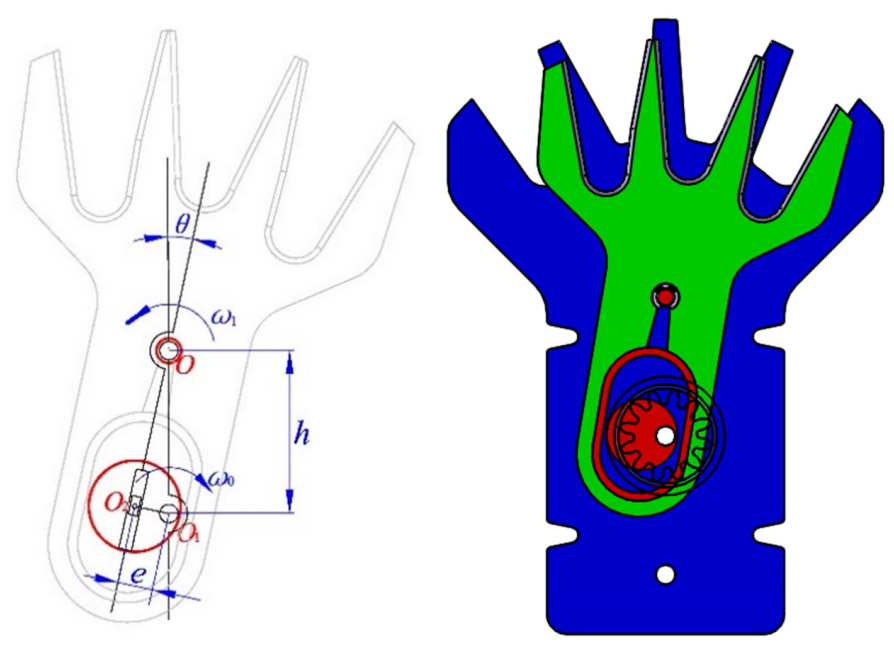

Figure 5. Generation of reciprocating motion of the moving blade ( $O$ is the rotating center of the moving blade (green), $\mathrm{O}_{1}$ is the rotating center of the inner gear and the eccentric wheel (red), $\mathrm{O}_{2}$ is the center of the eccentric wheel, $e$ is the eccentricity of the eccentric wheel, $\omega_{0}$ is the angular speed of the driving motor, $\omega_{1}$ is the swing angular speed of the moving blade, and $\theta$ is the swing angle of the moving blade).

According to the kinematic relationship, the coordinates of the eccentric wheel's center $\left(\mathrm{O}_{2}\right)$ is given by

$$
\left\{\begin{array}{c}
x_{\mathrm{O}_{2}}=L_{\mathrm{OO}_{2}} \sin \theta=e \sin \omega_{0} t \\
y_{\mathrm{O}_{2}}=L_{\mathrm{OO}_{2}} \cos \theta=h-e \cos \omega_{0} t
\end{array}\right.
$$

where $L_{\mathrm{OO}_{2}}$ is the distance between $O$ and $\mathrm{O}_{2}(\mathrm{~mm}), h$ is the length between point $\mathrm{O}_{1}$ and point $O(\mathrm{~mm}), e$ is the eccentricity of the eccentric wheel $(\mathrm{mm}), \theta$ is the swing angle of the moving blade (rad), $\omega_{0}$ is the angular speed of the driving motor ( $\left.\mathrm{rad} / \mathrm{s}\right)$. The swing angle is an important parameter for the cutting blades. According to Equation (2), the swing angle meets the following Equation:

$$
\tan \theta=\frac{e \sin \omega_{0} t}{h-e \cos \omega_{0} t}
$$

Then, $\theta$ can be obtained by

$$
\theta=\arctan \left(\frac{e \sin \omega_{0} t}{h-e \cos \omega_{0} t}\right)
$$

The swing angular speed of the moving blade $\omega_{1}(\mathrm{rad} / \mathrm{s})$ is determined by

$$
\omega_{1}=\frac{d \theta}{d t}=\frac{h e \omega_{0} \cos \omega_{0} t-e^{2} \omega_{0}}{e^{2}+h^{2}-2 h e \cos \omega_{0} t}
$$

The swing limit angle of the moving blade can be derived as

$$
\phi=2 \times \theta_{\max }=2 \times \arcsin \left(\frac{e}{h}\right) \times \frac{360}{2 \pi}
$$

According to the parameters of the chosen blades, $e=6 \mathrm{~mm}, h=35 \mathrm{~mm}$, the maximum swing angle of the moving blade can be calculated as $19.74^{\circ}$. This swing angle could permit that the moving blade sweeps the full cutting gap with respect to the fixed blade in one reciprocating cycle. 


\subsubsection{Determination of the Number of Cutter Units}

The knife system could adjust to different shapes and sizes of plants. By increasing or decreasing the number of cutter units, the contour of the knife system could be changed. A common shrub shape is a ball-like sphere and the knife system needs to form an arc, as shown in Figure 6.

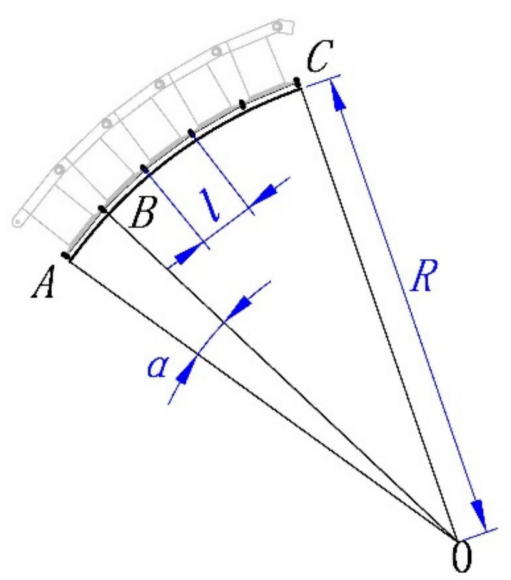

Figure 6. Structure of an arc-shape knife, $l$ is the linear length of one cutter unit (mm), $R$ is the radius of the arc formed by cutter units (mm), and $\alpha$ is the angle of the knife unit's arc (rad).

The relation between the linear length and arc length is shown below

$$
l=\sqrt{2 R^{2}(1-\cos \alpha)}=\sqrt{4 R^{2} \sin ^{2} \frac{\alpha}{2}} \approx \sqrt{R^{2} \alpha^{2}}=R \alpha=L_{1}
$$

where $L_{1}$ is the arc length of the cutter unit (mm). If $L$ is the total arc length determined by the shape of the plant, the number of cutter units required $n$ can be calculated by

$$
n=\frac{L}{L_{1}} \approx \frac{L}{l}
$$

\subsubsection{Determination of the Driving Motor Speed}

The cutting ability of the blades is highly related to the frequency of the cutting motion, which is equal to the rotating speed of the driving motor. To keep the knife system lightweight while ensuring enough cutting power, a small DC motor (model JGB37-545, weight $260 \mathrm{~g}$ ) with a rated speed of $1000 \mathrm{r} / \mathrm{min}$ and rated torque of $0.8 \mathrm{~kg} \cdot \mathrm{cm}$ was chosen for each cutter unit. After the cutter units and the knife system were assembled, the driving motor was set to run at different speeds to cut branches of different diameters, and the optimal driving motor speed was determined through experiments.

\section{Experiments}

This section introduces the experimental setup for determining the optimal working parameters, i.e., the cutting frequency of the cutter unit and the rotating speed of the rotary base, of the designed form trimming machine, and for evaluating the performance of the trimming operation.

\subsection{Determination of the Cutting Frequency of the Cutter Unit}

The driving motor of the cutter unit has a maximum rotating speed of about $1000 \mathrm{r} / \mathrm{min}$, i.e., the maximum cutting frequency of the cutting blades is around $16.7 \mathrm{~Hz}$. To test the cutting performance of the cutter unit under different cutting frequencies, the driving motor was controlled to run at four different speeds: 450, 650, 850, and $1000 \mathrm{r} / \mathrm{min}$, to trim the branches of Aglaia odorata, a widely planted shrub in China. The diameters of the 
branches on the plant ranged from 1 to $5 \mathrm{~mm}$. The branches, both cut off and un-cut off, were collected and their diameters were measured.

\subsection{Determination of the Rotating Speed of the Rotary Base}

The rotating speed of the rotary base is another key working parameter of the trimming machine. To determine the optimal rotating speed, the rotary base was controlled to run at five different speeds: 7.5, 10.5, 13.5, 16.5 and $19.5 \mathrm{r} / \mathrm{min}$. The tested shrub plant was Fagraea ceilanica, with its size before trimming being around $500 \mathrm{~mm}$ and the average moisture of its branches being $36.2 \%$.

To evaluate the performance of the trimming operation, the contour of the knife system and the contour of the plant after trimming were compared. To make a quantitative comparison, the trimming performance was recorded by a photography system (German $\mathrm{PCO}$, series dimax HD+, $1920 \times 1440$ resolution). The experimental setup is shown in Figure 7. A grid paper was put in the background, and a white paper with angle marks were stuck on the ground. The photography system was placed in front of the trimming machine. After the trimming was completed, the contours of the knife system and the trimmed plants were captured. To record a full view of the plant contours, the plant was put in 12 different angle positions, and the angle marks on the ground were used for alignment. Pictures of contours taken by the photography system are shown in Figure 8.

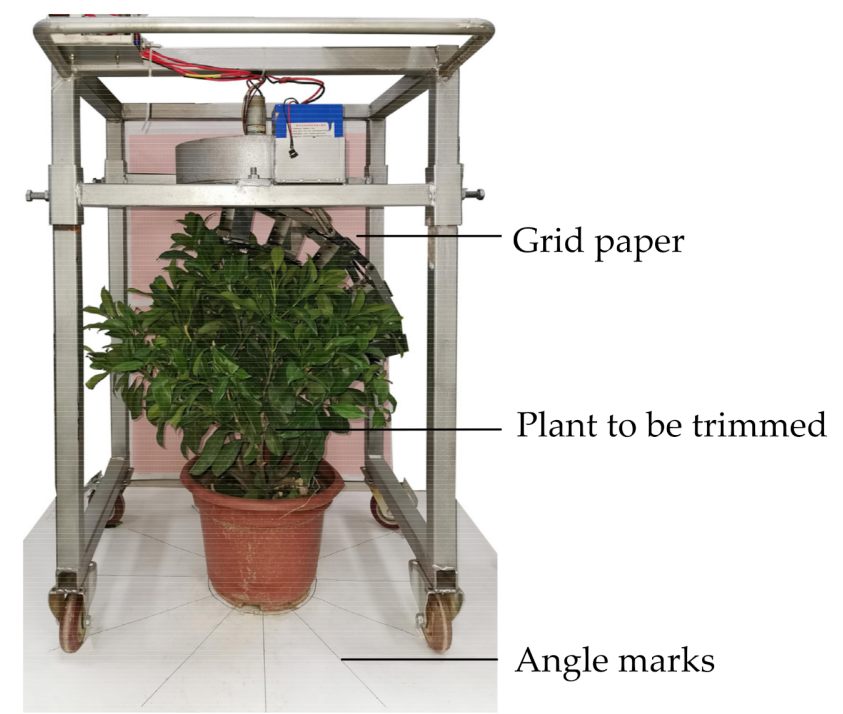

Figure 7. Experimental setup.

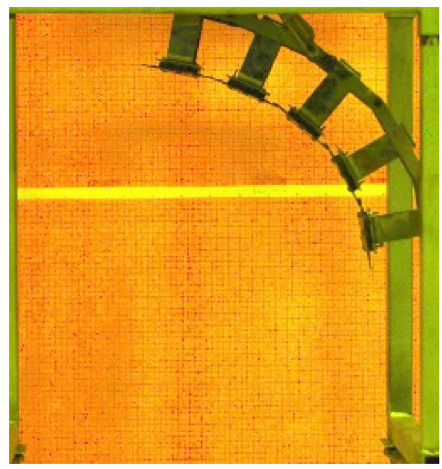

(a)

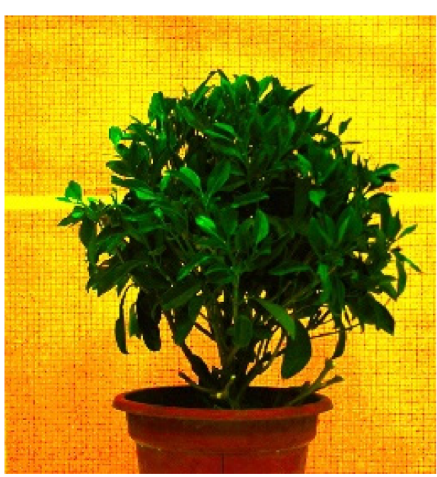

(b)

Figure 8. Pictures of contours taken by the photography system (a) Knife system; (b) Shrub plant after trimming. 
After trimming, the pictures were then uploaded to a PC with a MATLAB program for processing and analysis. The profiles of the knife system and the plant after image processing are shown in Figure 9. Feature points $\left(x_{i}, y_{i}\right)$ were extracted from the profile of the knife system, and $\left(a_{\mathrm{i}}, b_{i}\right)$ were extracted from the profile of the plant.

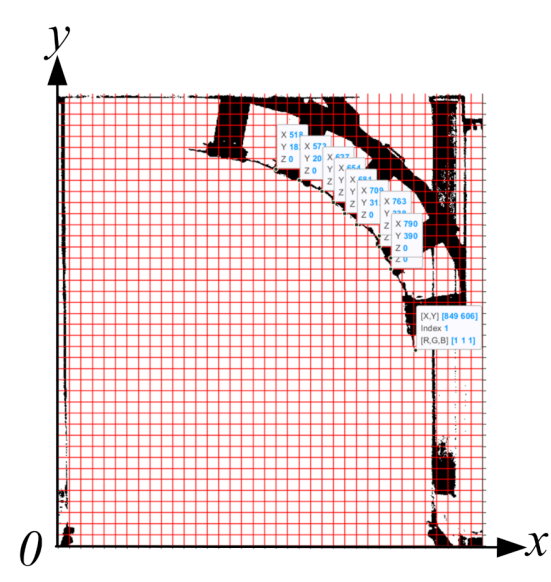

(a)

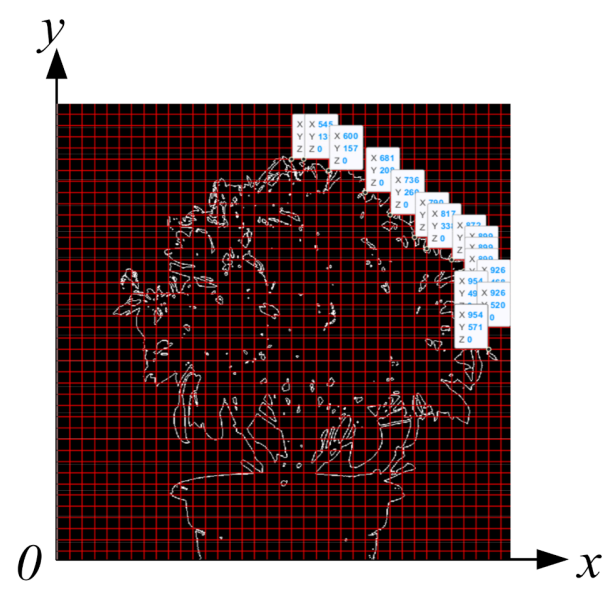

(b)

Figure 9. Profiles generated after image processing (a) Knife system; (b) Plant.

The overall relative deviation of the plant profiles from the profile of the knife system can be calculated by the following equation

$$
E_{S}=\frac{1}{m} \times \frac{1}{k} \times \sum_{j=1}^{m} \sum_{i=1}^{k}\left[\frac{\sqrt{\left(a_{i}-x_{i}\right)^{2}}}{x_{i}}+\frac{\sqrt{\left(b_{i}-y_{i}\right)^{2}}}{y_{i}}\right]
$$

where $E_{S}$ is the overall relative deviation, $m$ is the number of pictures taken for each trimmed plant and $m=12, k$ is the number of feature points extracted in each picture, $\left(a_{\mathrm{i}}, b_{\mathrm{i}}\right)$ are the coordinates of feature points of the trimmed plant $(\mathrm{mm}),\left(x_{\mathrm{i}}, y_{\mathrm{i}}\right)$ are the coordinates of feature points of the knife system $(\mathrm{mm})$. The similarity $S$ between profile of the trimmed plant and the profile of the knife system can be calculated by

$$
S=\left(1-E_{S}\right) \times 100 \%
$$

The second index for evaluating the performance of the machine was the time consumed for each complete trimming. During the experiments, the knife system was rotated for at least two circles. If the performance was not desirable, more rotations were carried out.

\subsection{Adaptability Test}

It is desirable that the designed trimming machine can work on different shrub plants. After the cutting frequency and the rotating speed of the rotary base were determined, the adaptability of the machine was tested. A total of five common shrub plants, Aglaia odorata, Murraya paniculate, Camellia oleifera, Osmanthus fragrans, Radermachera sinica, were chosen to be trimmed by the machine. The average diameters and moisture contents of the branches were measured before the test and are listed in the Table 2. 
Table 2. Average diameters and moisture contents of the branches from the five shrub plants.

\begin{tabular}{ccc}
\hline Plant & $\begin{array}{c}\text { Average Diameter of } \\
\text { Branches }(\mathbf{m m})\end{array}$ & $\begin{array}{c}\text { Average Moisture Content of } \\
\text { Branches (\%) }\end{array}$ \\
\hline Aglaia odorata & 3.61 & 47.07 \\
Murraya paniculate & 3.54 & 50.26 \\
Camellia oleifera & 3.73 & 40.92 \\
Osmanthus fragrans & 3.74 & 39.52 \\
Radermachera sinica & 3.65 & 45.03 \\
\hline
\end{tabular}

\section{Results and Discussion}

\subsection{Determination of the Cutting Frequency of the Cutter Unit}

Table 3 shows the performance of the cutter unit under different driving motor speeds/cutting frequencies. The cutting capability of the cutter unit generally improved with an increase in the driving motor speed. Under the lowest speed $450 \mathrm{r} / \mathrm{min}$, the cutter unit could only cut off the thinnest branches. Under the highest speed $1000 \mathrm{r} / \mathrm{min}$, the cutter unit could cut off $4.5 \mathrm{~mm}$ branches in one run, while branches thicker than $5 \mathrm{~mm}$ were too strong for the cutter unit. As reported in [26], the cutting energy required for cutting Miscanthus x giganteus stems was proportional to the stem diameter and the cutting energy from the blade was directly proportional to the cutting speed. For the cutter unit in this study, a higher cutting frequency meant a faster cutting speed of the moving blade, and thus provided more cutting energy.

Table 3. Performance of the cutter unit under different driving motor speeds/cutting frequencies.

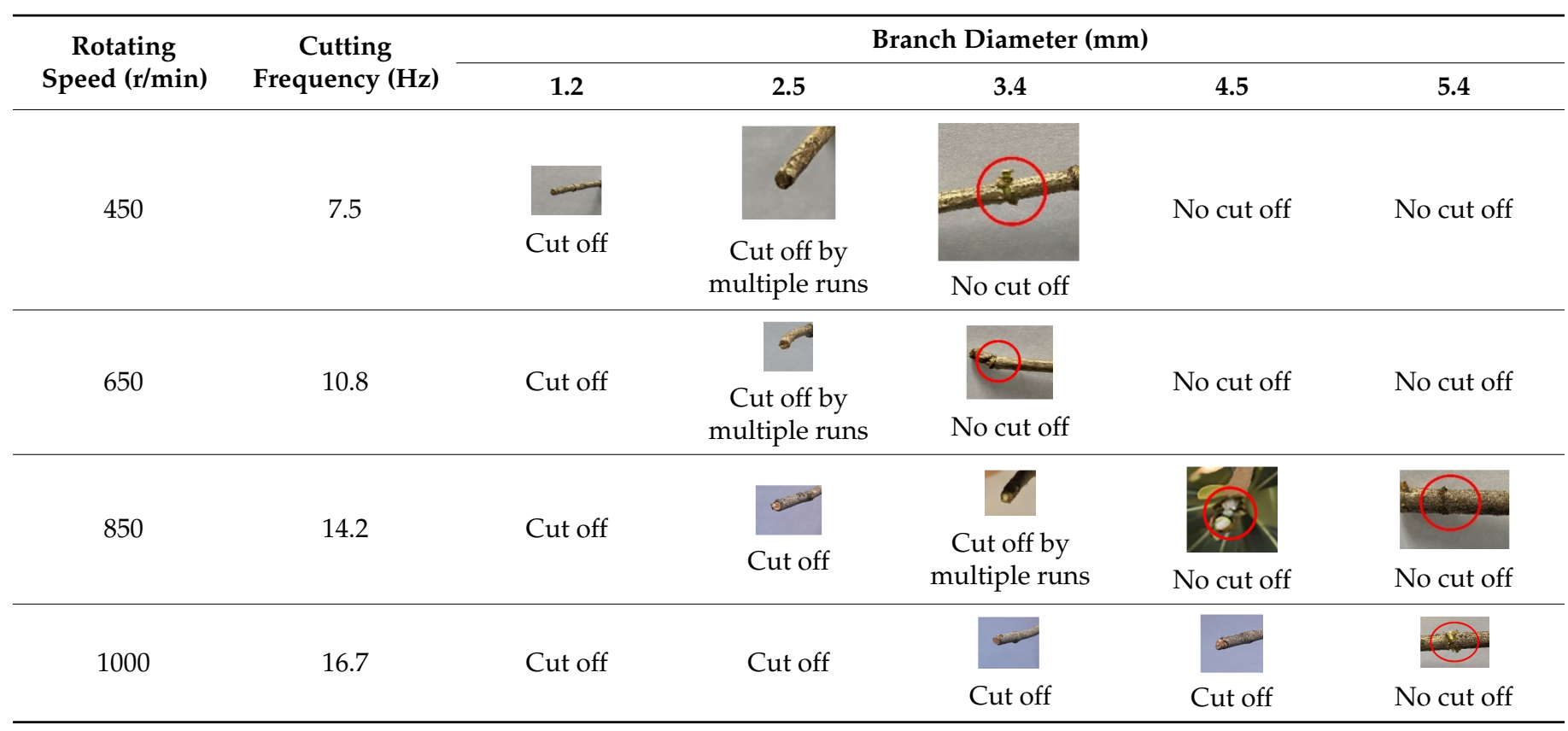

Generally, the branch diameters of small shrub plants are smaller than $5 \mathrm{~mm}$, and the designed cutter unit will be capable of trimming them. A shrub plant with branches thicker than $5 \mathrm{~mm}$ would be a plant too large for the trimming machine designed in this work. Since the cutter unit performed best under the highest driving motor speed, $1000 \mathrm{r} / \mathrm{min}$, or $16.7 \mathrm{~Hz}$ cutting frequency was determined to be the optimal working parameter for the cutter unit. 


\subsection{Determination of the Rotating Speed of the Rotary Base}

The trimming operation was performed when the rotary base was commanded to turn at different speeds. Taking the consumed time and similarity as the evaluation indexes, the results of the experiments were calculated and are listed in Table 4 as follows.

Table 4. Trimming performance under different rotating speeds of the rotary base.

\begin{tabular}{cccc}
\hline Rotating Speed (r/min) & Trimming Circle & Time Consumed (s) & Similarity (\%) \\
\hline 7.5 & 2 & 16 & 96.38 \\
10.5 & 2 & 11.43 & 96.18 \\
13.5 & 2 & 8.89 & 96.45 \\
16.5 & 3 & 10.91 & 96.01 \\
19.5 & 4 & 12.31 & 97.67 \\
\hline
\end{tabular}

From Table 4, the trimming operation under all rotating speeds could be completed with desirable performance, similarities all above $96 \%$. However, during the experiments, it was noticed that when the rotating speed of the rotary base was too fast, larger than $13.5 \mathrm{r} / \mathrm{min}$, the branches missed by the cutter units increased and more circles were required to complete a desirable trimming. A speed lower than $13.5 \mathrm{r} / \mathrm{min}$ could also result in a good trimming effect, but the time consumed increased. Considering both efficiency and performance, the rotating speed of the rotary base was determined at $13.5 \mathrm{r} / \mathrm{min}$, and the trimming operation was to be completed in two circles with a corresponding time consumption of $8.89 \mathrm{~s}$.

\subsection{Adaptability Test}

In the adaptability test, the cutting frequency of the cutter unit was fixed at $16.7 \mathrm{~Hz}$ and the rotating speed of the rotary base was fixed at $13.5 \mathrm{r} / \mathrm{min}$. Each plant was trimmed by two rotations of the knife system. The results of the test are shown in Table 5 .

Table 5. Performance of the adaptability test.

\begin{tabular}{|c|c|c|c|c|c|}
\hline Plant & Aglaia odorata & Murraya exotica & Camellia oleifera & Osmanthus fragrans & Radermachera sinica \\
\hline Form before & & & & & \\
\hline \multicolumn{6}{|c|}{ Form after trimming } \\
\hline Similarity (\%) & 94.87 & 93.79 & 94.32 & 94.95 & 95.49 \\
\hline
\end{tabular}

It can be seen from Table 5 that all five plants were successfully trimmed by the designed form trimming machine, and the profile of the knife system and the profile of the trimmed plants matched well. As the calculations show, the overall similarity was above $93 \%$. This confirms that the designed form trimming machine could adapt to different shrub plants.

However, this similarity level was lower than the anticipated performance. As a preliminary analysis, the reason would be the differences in the branch densities and strengths. The plants Aglaia odorata, Murraya paniculate, and Camellia oleifera, which resulted in the smallest similarities in the test, had thinner, softer branches and the trimming process was not as smooth as what was recorded in trimming the other plants. A different rotating speed of the rotary base would be more appropriate for those plants. The correlation between trimming performance and the branch density and strength can be taken as future studies to further improve the performance of the trimming machine. 


\section{Conclusions}

A form trimming machine for shrub plants was designed and tested in this study. The machine was mainly composed of three parts: a supporting frame, a rotary base and a knife system. Through the design, construction, and experimentation of the form trimming machine, the following conclusions are drawn:

(1) The two key working parameters, the cutting frequency of the cutter unit and the rotating speed of the rotary base, were determined to be $16.7 \mathrm{~Hz}$ and $13.5 \mathrm{r} / \mathrm{min}$ respectively. The trimming operation could be completed by two rotations of the knife system with a time consumption of $8.89 \mathrm{~s}$.

(2) Through a performance evaluation using a photography system and an imaging processing method, the similarities between the profile of the knife system and the profile of the trimmed plants were calculated. An overall similarity of $96 \%$ was obtained when the machine was tested to trim Fagraea ceilanica plants.

(3) Through an adaptability test using five different species of shrub plants, the overall similarity was above $93 \%$, which showed that the designed machine could meet the requirement of trimming various shrub plants with stable performance.

\section{Patent}

Ma, L.; Zhang, H.; Zong, W.; et al. A self-recognizing, self-locating form trimming machine based on machine vision for horticultural plants. Chinese Patent ZL201821161562.4, 2019-05-24.

Author Contributions: Conceptualization, L.M. and C.L.; methodology, M.L. and W.Z.; software, M.L.; validation, M.L., M.H. and Y.S.; formal analysis, M.L.; investigation, M.L. and M.H.; resources, L.M.; data curation, M.L.; writing—original draft preparation, M.L.; writing—review and editing, L.M., W.Z. and C.L.; visualization, M.L.; supervision, L.M.; project administration, L.M.; funding acquisition, C.L. All authors have read and agreed to the published version of the manuscript.

Funding: This project was funded by the Fundamental Research Funds for the Central Universities of China, grant number 2662019QD001.

Data Availability Statement: Not applicable.

Acknowledgments: The authors would like to thank He Zhang and Guangchao Zhan for their technical support in this work.

Conflicts of Interest: The authors declare no conflict of interest. The funder had no role in the design of the study; in the collection, analyses, or interpretation of data; in the writing of the manuscript, or in the decision to publish the results.

\section{References}

1. Chen, C.; Park, T.; Wang, X.; Piao, S.; Xu, B.; Chaturvedi, R.K.; Fuchs, R.; Brovkin, V.; Ciais, P.; Fensholt, R.; et al. China and India lead in greening of the world through land-use management. Nat. Sustain. 2019, 2, 122-129. [CrossRef]

2. National Romote Sensing Center of China (NRSCC). Global Urban Land Composite and Expansion in 2000-2020. Available online: http://www.chinageoss.cn/geoarc/en/pdf/2020C_en.zip (accessed on 6 February 2021).

3. Gokavi, N.; Mote, K.; Jayakumar, M.; Raghuramulu, Y.; Surendran, U. The effect of modified pruning and planting systems on growth, yield, labour use efficiency and economics of Arabica coffee. Sci. Hortic. 2021, 276, 109764. [CrossRef]

4. Wei, X.; Chen, D.; Liu, S.; Wang, X.; Gao, Z.; Wang, Y. Effect of trim on jujube transpiration in loess hilly region. Trans. Chin. Soc. Agric. Mach. 2014, 45, 194-202.

5. Pineda, M.; Yu, B.; Tian, Y.; Morante, N.; Salazar, S.; Hyde, P.T.; Setter, T.L.; Ceballos, H. Effect of pruning young branches on fruit and seed set in cassava. Front. Plant Sci. 2020, 11, 1107. [CrossRef] [PubMed]

6. Sun, J.; Gao, H.; Tian, J.; Du, C.; Guo, S. Development status and trends of protected horticulture in China. J. Nanjing Agric. Univ. 2019, 42, 594-604.

7. Reddy, K.A.; Babu, N.M.; Harini, L.; Srikanth, R.; Srinivas, J. Design and analysis of a revised grass trimming device. J. Sci. Ind. Res. 2010, 69, 39-42.

8. Mallick, Z. Optimization of operating parameters for a back-pack type grass trimmer. Int. J. Ind. Ergon. 2008, 38, 101-110. [CrossRef] 
9. Pandiselvam, R.; Manikantan, M.R.; Subhashree, N.; Mathew, A.C.; Balasubramanian, D.; Shameena Beegum, P.P.; Ramesh, S.V.; Niral, V.; Ranjini, T.N.; Hebbar, K.B. Correlation and principal component analysis of physical properties of tender coconut (Cocos nucifera L.) in relation to the development of trimming machine. J. Food Process Eng. 2019, 42, e13217. [CrossRef]

10. Sitorus, A.; Fauzi, A.; Ramadhan, G.; Hasan, A.R.; Karyadi, A. Conceptual Design of Harvesters Knife for Chinese Spinach (Ipomoea Reptans Poir.): Cad Approach. 2018 International Conference on Computing, Engineering, and Design (ICCED), Bangkok, Thailand, 6-8 September 2018; pp. 7-12. [CrossRef]

11. Fujisawa, A.; Chida, Y. Optimization of an installation angle of a root-cutting blade for an automatic spinach harvester. J. Phys. Conf. Ser. 2016, 744, 012135. [CrossRef]

12. Tuijl, V.B.A.J.; Tielen, A.P.M.; Mencarelli, A.; Hemming, J. Structured design of a novel end-effector for a bush trimming robot. In Proceedings of the European Conference on Agricultural Engineering AgEng2018, Wageningen, The Netherlands, 8-12 July 2018; pp. 188-196.

13. Kaljaca, D.; Vroegindeweij, B.; Mencarelli, A.; van Henten, E. Coverage trajectory planning for a bush trimming robot arm. J. Field Robot. 2020, 37, 1148. [CrossRef]

14. Qiu, J.; Wu, M.; Guan, C.; Fang, Y.; Li, X. Design and experiment of chopping device with dynamic fixed knife coaxial for rice straw. Trans. Chin. Soc. Agric. Eng. 2015, 31, 11-19.

15. Lin, J.; Ma, T.; Lu, Z.; Li, B.; Song, J.; Lv, Q. Design and experiment of the surveying and mapping device for the movement characteristics of corn stubble cutting with disc cutting knife. Agric. Res. Arid Areas 2017, 35, 271-281.

16. Yang, Y.; Xu, J.; Wang, J.; Zhang, Q.; Liu, Q. Design of a new chopper for corn stalk and wear test of its moving knives. J. Jilin Agric. Univ. 2010, 32, 468-472.

17. He, L.; Schupp, J. Sensing and automation in pruning of apple trees: A Review. Agronomy 2018, 8, 211. [CrossRef]

18. Strnad, D.; Kohek, S.; Benes, B.; Kolmanic, S.; Zalik, B. A framework for multi-objective optimization of virtual tree pruning based on growth simulation. Expert Syst. Appl. 2020, 162, 113792. [CrossRef]

19. Zahid, A.; He, L.; Zeng, L.; Choi, D.; Schupp, J.; Heinemann, P. Development of a robotic end-effector for apple tree pruning. Trans. ASABE 2020, 63, 847-856. [CrossRef]

20. Souza, V.H.S.; Santos, A.A.R.; Costa, A.L.G.; Santos, F.L.; Magalhaes, R.R. Evaluation of the interaction between a harvester rod and a coffee branch based on finite element analysis. Comput. Electron. Agric. 2018, 150, 476-483. [CrossRef]

21. Wu, L.; Yang, Z.; Duan, J.; Wang, L.; Wang, W.; Liu, J.; Wang, L. Experiment on influencing factors of cutting force of blades of trim tool for longan branch. Trans. Chin. Soc. Agric. Eng. 2012, 28, 8-14.

22. Jarimopas, B.; Ruttanadat, N.; Terdwongworakul, A. An automatic trimming machine for young coconut fruit. Biosyst. Eng. 2009, 103, 167-175. [CrossRef]

23. Chen, C.; Wang, X.; He, Z. Design of header for rape harvesting using grain combine harvester. Trans. Chin. Soc. Agric. Mach. 2003, 34, 54-56.

24. Li, P.; Liao, Q.; Li, L.; Han, C.; Huang, P.; Li, H. Design and experiment of the main device of 4SY-1.8 modified rape windrower. Trans. Chin. Soc. Agric. Mach. 2014, 45, 53-58.

25. Liu, W.; Huang, X.; Ma, L.; Zong, W.; Zhu, Y. Design and experiment of special header of oil sunflower combine harvester. Trans. Chin. Soc. Agric. Mach. 2020, 51, 83-88.

26. Johnson, P.C.; Clementson, C.L.; Mathanker, S.K.; Grift, T.E.; Hansen, A.C. Cutting energy characteristics of Miscanthus x giganteus stems with varying oblique angle and cutting speed. Biosyst. Eng. 2012, 112, 42-48. [CrossRef] 